\title{
Reduced dimethyl sulfoxide concentrations successfully cryopreserve human hematopoietic stem cells with multi-lineage long-term engraftment ability in mice
}

\author{
Renata Gilfanova ${ }^{1,3}$, Kirsten M. Auclair ${ }^{1}$, Alvin Hui ${ }^{1}$, Philip J. Norris ${ }^{1,2}$, Marcus O. Muench ${ }^{1,2, *}$ \\ ${ }^{1}$ Vitalant Research Institute, San Francisco, California, USA \\ ${ }^{2}$ Department of Laboratory Medicine, University of California, San Francisco, California, USA \\ ${ }^{3}$ Blood and Marrow Transplantation, Stanford University, Stanford, California, USA
}

\section{A R T I C L E I N F O}

\section{Article History:}

Received 9 April 2021

Accepted 7 July 2021

\section{Key Words:}

cryopreservation

cryoprotectants

dimethyl sulfoxide

hematopoietic stem cell transplantation

immunodeficient mice

stem cells

\begin{abstract}
A B S T R A C T
Background aims: The cryopreservation of hematopoietic stem cells (HSCs) in dimethyl sulfoxide (DMSO) is used widely, but DMSO toxicity in transplant patients and the effects of DMSO on the normal function of cryopreserved cells are concerns. To address these issues, in vitro and clinical studies have explored using reduced concentrations of DMSO for cryopreservation. However, the effect of reducing DMSO concentration on the efficient cryopreservation of HSCs has not been directly measured.

Methods: Cryopreservation of human bone marrow using 10\%, 7.5\% and 5\% DMSO concentrations was examined. Cell counting, flow cytometry and colony assays were used to analyze different cell populations. The recovery of stem cells was enumerated using extreme limiting dilution analysis of long-term multi-lineage engraftment in immunodeficient mice. Four different methods of analyzing human engraftment were compared to ascertain stem cell engraftment: (i) engraftment of $\mathrm{CD}_{3} 3^{+}$myeloid, $\mathrm{CD} 19^{+} \mathrm{B}$-lymphoid, $\mathrm{CD} 235 \mathrm{a}^{+}$erythroid and $\mathrm{CD} 34^{+}$progenitors; (ii) engraftment of the same four populations plus $\mathrm{CD} 41^{+} \mathrm{CD} 42 \mathrm{~b}^{+}$platelets; (iii) engraftment of $\mathrm{CD} 34^{++} \mathrm{CD} 133^{+}$cells; and (iv) engraftment of $\mathrm{CD} 34^{++} \mathrm{CD} 38^{-}$cells.

Results: Hematopoietic colony-forming, $\mathrm{CD} 34^{++/+}, \mathrm{CD} 34^{++} \mathrm{CD} 133^{+}$and $\mathrm{CD} 34^{++} \mathrm{CD} 38^{-}$cells were as well preserved with $5 \%$ DMSO as they were with the higher concentrations tested. The estimates of stem cell frequencies made in the xenogeneic transplant model did not show any significant detrimental effect of using lower concentrations of DMSO. Comparison of the different methods of gauging stem cell engraftment in mice led to different estimates of stem cell numbers, but overall, all measures found that reduced concentrations of DMSO supported the cryopreservation of HSCs.

Conclusion: Cryopreservation of HSCs in DMSO concentrations as low as $5 \%$ is effective.

(c) 2021 International Society for Cell \& Gene Therapy. Published by Elsevier Inc. This is an open access article under the CC BY license (http://creativecommons.org/licenses/by/4.0/)
\end{abstract}

\section{Introduction}

Hematopoietic stem cell (HSC) transplantation is a widely used treatment for patients suffering from inherited diseases, cancer and other acquired diseases [1]. Cryopreservation with media containing dimethyl sulfoxide (DMSO) is a critical part of the transplantation procedure, as the use of freshly harvested cells is often not possible. DMSO is a membrane-permeable cryopreservation agent that functions by reducing the crystallization of water that otherwise results in the concentration of solutes and mechanical damage leading to cell death [2]. Although an effective cryopreservation agent, DMSO can also release contaminants from plasticware [3] and affect the

\footnotetext{
* Correspondence: Marcus O. Muench, PhD, Vitalant Research Institute, 270 Masonic Ave, San Francisco, California 94118, USA

E-mail address: mmuench@vitalant.org (M.O. Muench).
}

normal functioning of cells [4,5], and DMSO-containing transplants can cause a multitude of patient side effects [6-10]. These adverse effects can include allergic reactions, owing to histamine release; gastrointestinal reactions, such as nausea, vomiting, diarrhea, pain and cramping; cardiovascular and respiratory reactions, such as hypotension, hypertension, decreased heart rate, bradycardia and respiratory symptoms; and other adverse reactions, including hyponatremia, urethral irritation, headache, fever, chills, weakness, sedation and even death.

Reducing the concentration of DMSO used for cryopreservation is a straightforward means to mitigate its detrimental effects on cells and patients. Although cryopreservation in freezing medium with $10 \%$ DMSO may be considered the historical standard [11-16], recent research has suggested that lower levels may be used effectively. Reducing DMSO levels to $5 \%$ has been shown to be effective in maintaining erythroid precursors from umbilical cord blood [17]. 
Similarly, erythroid and myeloid colony-forming cells (CFCs) have been shown to be maintained in cryopreservation media with only $5-7.5 \%$ DMSO [18-21]. Flow cytometric analyses of $\mathrm{CD} 34^{+}$precursors have further demonstrated enhanced viability when cells are frozen in $5 \%$ rather than $10 \%$ DMSO [22].

Clinical results from grafts cryopreserved with reduced DMSO concentrations have been positive. In cancer patients receiving autologous transplants, the time to engraftment is similar for grafts cryopreserved in $5 \%$ or $10 \%$ DMSO, and long-term recoveries are also similar $[23,24]$. Three concentrations of DMSO (10\%, 7.5\% and 5\%) were tested in a prospective randomized study of cancer patients, and all concentrations were shown to be equally effective in preserving the cells responsible for timely peripheral blood cell reconstitution [25]. Moreover, adverse events associated with stem cell infusion were significantly reduced from $41.7 \%$ with $10 \%$ DMSO to $19.1 \%$ with $5 \%$ DMSO. Nonetheless, a diversity of practices for the cryopreservation of HSCs still exist, with DMSO most often used at a concentration of $5-10 \%$ [26].

In determining the effects of cryopreservation media on HSCs, the primary difficulty is the lack of definitive in vitro measures of these cells. Flow cytometry and CFC assays provide information on progenitors-an important graft component-but these are surrogate assays of the effects of cryopreservation on HSCs. Clinical measures such as time to engraftment of leukocytes and platelets and even hematopoietic engraftment after several years are insensitive measures of the robustness of the HSC pool, as they are only sensitive when hematopoietic engraftment and recovery are poor, which transplant protocols actively aim to avoid [27]. In light of these limitations, the authors have used a xenogeneic transplant model to measure the effects of DMSO concentration on the cryopreservation of human HSCs. Using immunodeficient mice, the numbers of functional HSCs recovered from cryopreservation with $5 \%, 7.5 \%$ and $10 \%$ DMSO were quantified using extreme limiting dilution analysis (ELDA) [28].

\section{Methods}

\section{Human bone marrow}

Mid-gestation bone marrow was used in this study owing to the sufficient quantity of cells that could be recovered from a single specimen and the ability of these cells to vigorously engraft immunodeficient mice [29]. Samples came from San Francisco General Hospital under approval of the institutional review board at the University of California San Francisco (institutional review board no. 10-00768) in accordance with the Declaration of Helsinki. Written informed consent was obtained by clinic staff, but donors remained anonymous to the authors of this study. The gestational age of the specimens (17-22 weeks) was estimated based on foot length measurements.

\section{Cryopreservation and cell recovery}

Cryopreservation was performed using a new ampule of DMSO (D2650; Sigma-Aldrich, St Louis, MO, USA) diluted in heat-inactivated fetal bovine serum at $5 \%, 7.5 \%$ or $10 \%$ final concentration. CryoStor CS10 (BioLife Solutions, Bothell, WA, USA), a commercial current Good Manufacturing Practice-grade cryopreservative with 10\% DMSO and defined components, was also used. Cells were frozen at $9 \times 10^{6}$ cells $/ \mathrm{mL}$ to $19 \times 10^{6}$ cells $/ \mathrm{mL}$, centrifuged, depleted of media and suspended in $1 \mathrm{~mL}$ of cryoprotectant. Within $5 \mathrm{~min}$, cryovials were placed into CoolCell FTS30 freezing containers (Corning, Corning, NY, USA), which provide a $-1^{\circ} \mathrm{C} / \mathrm{min}$ freezing rate, and transferred to $\mathrm{a}-80^{\circ} \mathrm{C}$ freezer. One day later, the cells were moved to liquid nitrogen for $22-56$ days.

Cells were warmed quickly in a $37^{\circ} \mathrm{C}$ water bath until almost fully thawed and then slowly mixed with warm phosphate-buffered saline. Cells were washed free of DMSO by $200 \times$ g centrifugation at $4^{\circ} \mathrm{C}$ for 5 min to avoid the effects of DMSO in culture or transplanted mice.

\section{Cell counting and flow cytometric analysis}

A Cellometer K2 (Nexcelom Bioscience, Lawrence, MA, USA) was used to count cells, with viability measured based on Acridine Orange/Propidium Iodide staining. Flow cytometry was performed as described [30]. Antibodies used were purchased from BioLegend (San Diego, CA, USA) and Miltenyi Biotec (Auburn, CA, USA) as listed in supplementary Table 1 . Flow cytometry data were analyzed using FlowJo v9 software (FlowJo, Ashland, OR, USA).

\section{Cell cultures}

Live cell numbers and viability frequencies were determined after thawing and then culturing in 24-well plates at $0.5 \times 10^{6}$ cells to $1.0 \times 10^{6}$ cells in $1 \mathrm{~mL}$ using serum-free medium [31] with recombinant human IL-3 $(20 \mathrm{ng} / \mathrm{mL})$ and kit ligand $(50 \mathrm{ng} / \mathrm{mL})$ with both cytokines purchased from PeproTech (Cranbury, NJ, USA). After 5 days, cells were counted and analyzed by flow cytometry. CFC assays were performed in quadruplicate using the same medium and cytokines suspended in 0.36\% low melting temperature SeaPlaque agarose (Lonza, Rockland, ME, USA) and grown in $35 \mathrm{~mm}^{2}$ culture dishes (BD Biosciences, Franklin Lakes, NJ, USA). A total of $5.0 \times 10^{4}$ cells were plated for each $1 \mathrm{~mL}$ of culture. CFCs were scored after 14 days of growth as progenitors producing at least 50 cells [32].

\section{Xenografting of mice}

Animal experimentation had approval and oversight of the institutional animal care and use committee at Labcorp Early Development Laboratories Inc. (San Carlos, CA, USA; animal welfare assurance no. A3367-01) under protocol IAC 2235. Experiments adhered to the principles of the current version of the National Research Council's Guide for the Care and Use of Laboratory Animals. Husbandry conditions have been previously detailed [33]. Euthanasia was performed according to the recommendations of the American Veterinary Medical Association.

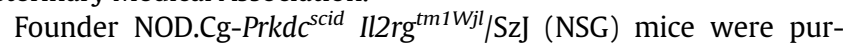
chased from The Jackson Laboratory (Bar Harbor, ME, USA) and bred at Vitalant Research Institute. At least 3 days prior to irradiation, the standard rodent diet was exchanged for irradiated Global 2018 rodent diet with 4100 ppm Uniprim (Envigo, Indianapolis, IN, USA) for 1 month. NSG mice $\geq 8$ weeks old were irradiated with $175 \mathrm{cGy} \mathrm{x}$ rays and approximately $3 \mathrm{~h}$ later transplanted with $1 \times 10^{6}$ cells, $3 \times 10^{5}$ cells, $1 \times 10^{5}$ cells or $3 \times 10^{4}$ cells as described [30]. A single bone marrow specimen was used for each of the two experiments. In the first experiment, mice of both sexes were distributed among the groups, and male mice were used in the second experiment.

Engraftment was analyzed $\geq 12$ weeks after transplant by flow cytometry as previously detailed [30]. Human leukocytes were identified by CD45 or $\beta 2$-microglobulin expression and lack of strong mouse marker (TER-119, CD45 and H-2Kd) expression. Engraftment was defined as the presence of $\mathrm{CD}_{3} 3^{+}$myeloid, $\mathrm{CD} 235^{+}$erythroid, CD $19^{+}$B-lymphoid and CD $34^{+}$hematopoietic precursors in the bone marrow. An untransplanted mouse was analyzed as a negative control. A transplanted mouse with more than five positive events for each of the four human antigens was considered to be fully engrafted [34]. The overall frequency of engraftment in the bone marrow was determined based on the frequency of human leukocytes and erythrocytes. Additional human lineages and precursor subsets were analyzed in some transplant recipients, including analysis of whole spleen cells, and used to perform ELDAs.

\section{Data presentation and statistical analysis}

Statistical analysis and charting were performed using Prism 9 (GraphPad Software, San Diego, CA, USA). The in vitro effects of different 
cryopreservation conditions were compared using one-way analysis of variance with Tukey's multiple comparison test. ELDA was used to quantify HSC frequencies, and the overall tests of differences in stem cell frequencies and pairwise comparisons were made using online software provided by Hu and Smyth [28]. A two-tailed paired $t$-test was used to compare bone marrow and spleen erythrocyte measurements. A $P \leq 0.05$ was considered significant. Data are presented as mean \pm standard error, with individual data shown. Heat maps were created using the mean results for different transplant groups.

\section{Results}

In vitro measures of progenitor survival after cryopreservation

With the exception of one measure, the recovery of cryopreserved bone marrow cells and progenitors did not differ significantly among the three concentrations of DMSO tested. After thawing, live cells were counted and colony-forming unit cell assays performed (Figure 1A). Reanimated cells were also placed in liquid culture to allow time for apoptosis to occur in damaged cells and to permit progenitor expansion to multiply minor differences among the groups. Flow cytometry was used to enumerate $\mathrm{CD} 34^{++/+}$progenitors as well as two subpopulations of primitive precursors containing HSCs (Figure 1B). With the exception of fewer $\mathrm{CD} 34^{++} \mathrm{CD} 38^{-}$cells seen in the $10 \%$ DMSO group compared with the 7.5\% DMSO group, no differences were observed in the cell fractions recovered from the cultures (Figure 1C).

\section{Effects of DMSO concentration on HSCS}

A total of 92 immunodeficient mice were transplanted with four doses of bone marrow cells cryopreserved using three concentrations of DMSO. Engraftment was evaluated 135 days after transplant based on the presence of four cell populations (Figure 2A), and ELDA was performed (Figure 2B). The highest frequency of HSCs was observed in the $5 \%$ DMSO group, but the difference was not significant. Similarly, in a second experiment, a total of 93 mice were analyzed 84 days after transplant, with the highest frequency of HSCs observed in the 7.5\% DMSO group, but, again, there were no significant differences among the four groups (Figure 2C). CryoStor CS10 was tested as an additional cryopreservation agent in the second experiment and performed very similar to

10\% DMSO. Overall, human engraftment levels in the bone marrow for the different groups of mice were similar for different cell doses, with a tendency toward lower percentages of DMSO resulting in the highest levels of chimerism (Figure 2D,E).

\section{Evaluation of alternative methods of gauging HSC engraftment}

Among the four cell types used to measure HSC engraftment in NSG mice, erythrocytes were generally the least frequently noted in the bone marrow. The authors examined whether splenocytes would be a better source of mature erythrocytes (Figure 3A). However, pairwise evaluations of the frequencies and numbers of $\mathrm{CD} 235 \mathrm{a}^{+}$events in the bone marrow and spleen clearly indicated that the former was a richer source of human erythrocytes.

The inclusion of $\mathrm{CD} 41^{+} \mathrm{CD} 42 \mathrm{~b}^{+}$platelet engraftment in the criteria for determining HSC engraftment was examined (Figure 3B). Fewer mice were deemed engrafted using this five-marker analysis, resulting in estimates of HSC frequencies that were decreased by more than half. In this analysis, the 5\% DMSO group had the highest HSC content, whereas the 7.5\% DMSO group had more HSCs based on the four-marker analysis (Figure 2C). Nonetheless, no significant differences were observed among the groups by including platelets in the engraftment criteria.

HSC engraftment was also evaluated by the presence of either of two primitive progenitor populations alone. ELDA, based on only $\mathrm{CD} 34^{++} \mathrm{CD} 133^{+}$cell engraftment (Figure $3 \mathrm{C}$ ), estimated the highest frequency of HSCs in the 7.5\% DMSO group, which differed significantly from the 5\% DMSO $(P=0.195)$ and CryoStor CS10 $(P=0.0269)$ groups but not the $10 \%$ DMSO group $(P=0.0541)$. Analysis using the more infrequent $\mathrm{CD} 34^{++} \mathrm{CD} 38^{-}$cell population resulted in the lowest estimates of HSC frequencies of all the analyses performed, with the 7.5\% DMSO group performing the best (Figure 3D). However, none of the groups differed significantly from one another.

\section{Discussion}

Concentrations of DMSO below 10\% are being evaluated for the cryopreservation of HSCs in an effort to minimize the unwanted side effects of DMSO on transplant patients. Cells, $\mathrm{CD} 34^{+}$progenitors and CFCs from umbilical cord blood and mobilized peripheral blood have been shown to

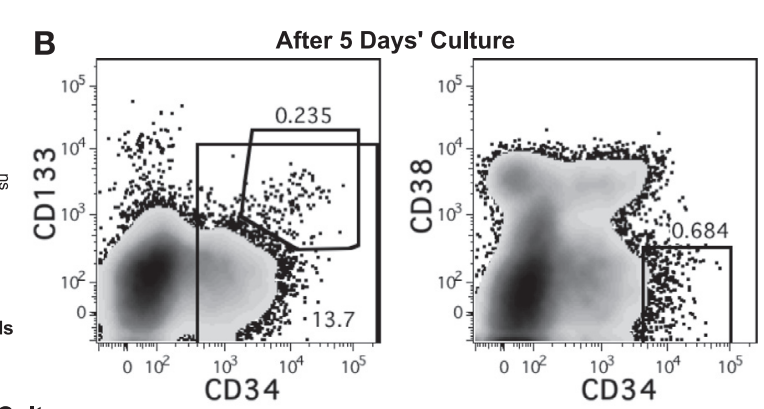

C

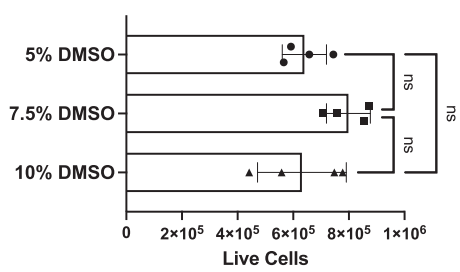

After Thawing

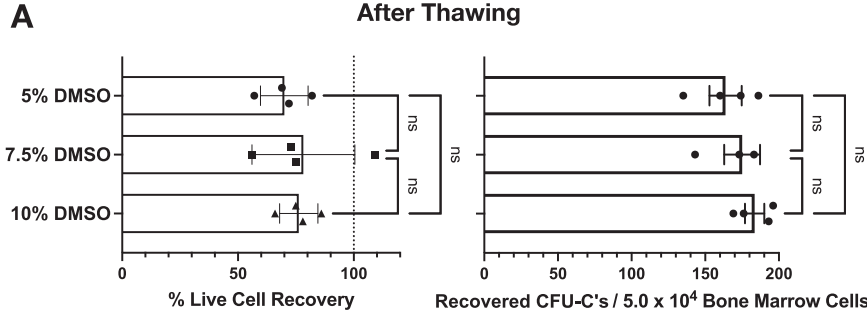

After 5 Days' Culture

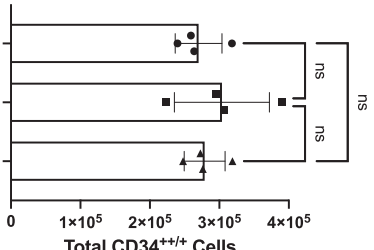

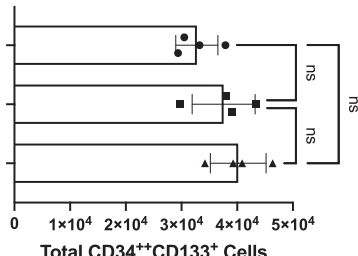

Total CD $34^{++}$CD $133^{+}$Cells

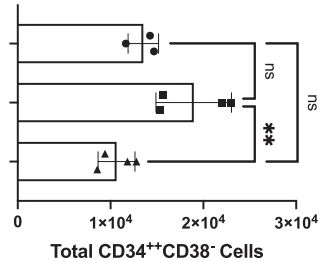

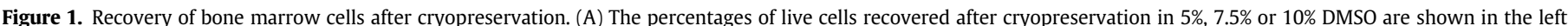

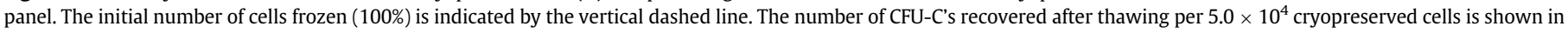

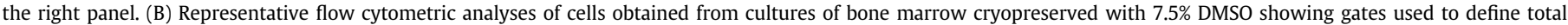

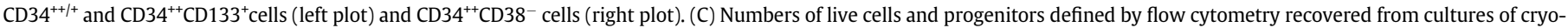

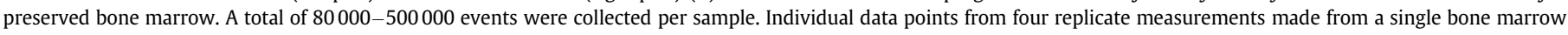
specimen at 17 weeks' gestation are indicated on the charts $(A)$ and $(C) .{ }^{* *} P=0.0089$. CFU-C's, colony-forming unit cells. 

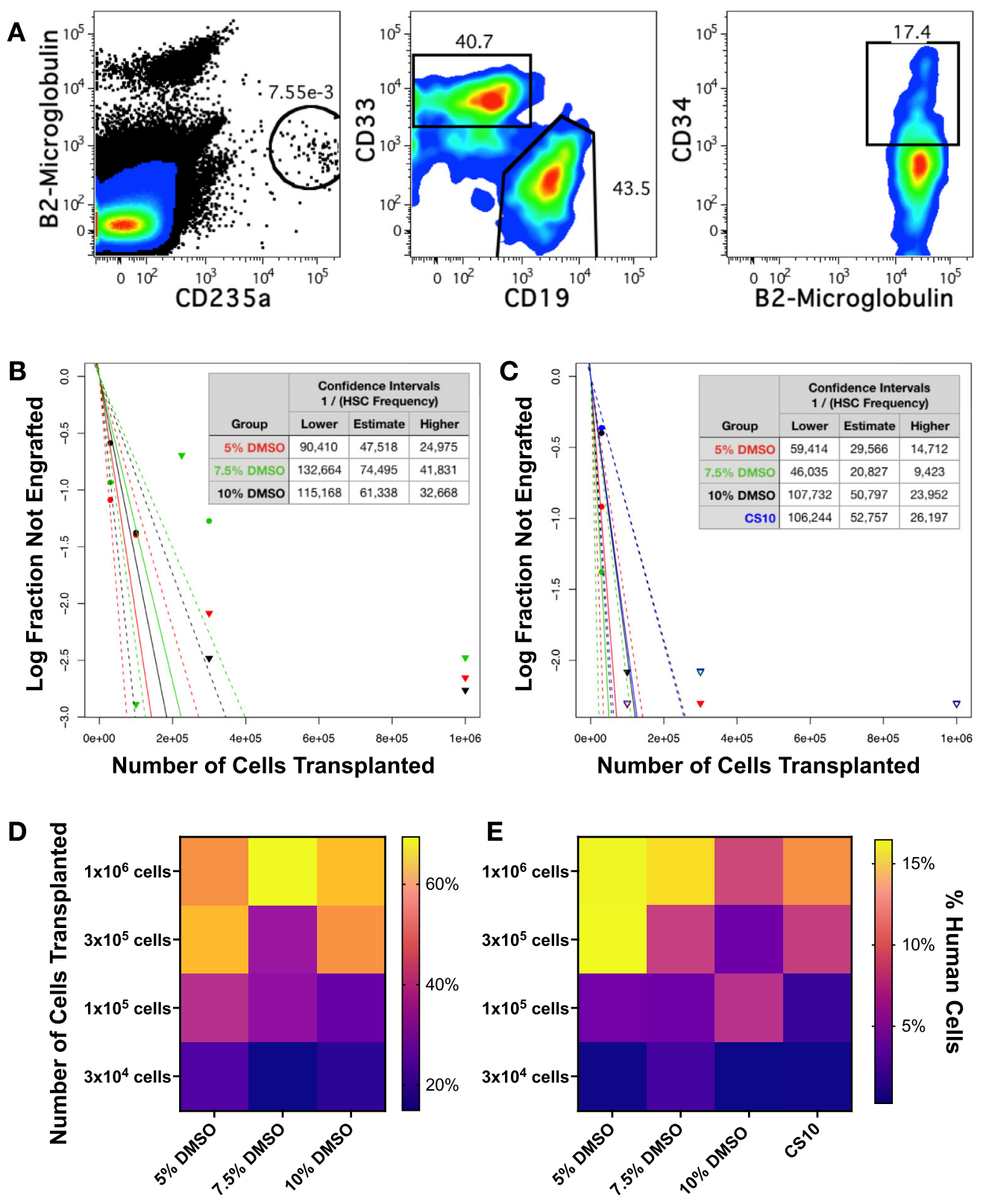

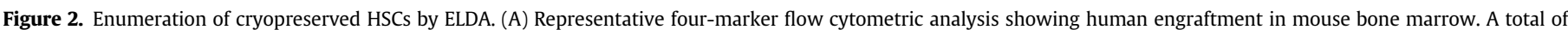

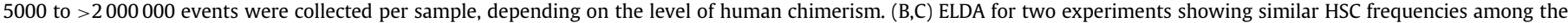

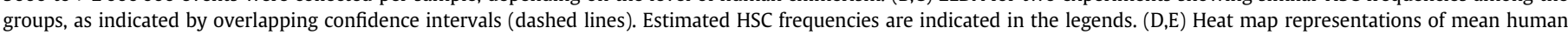
engraftment in the bone marrow for each of the transplant groups. CS10, CryoStor CS10.

be cryopreserved with high recovery rates at DMSO concentrations of $5-7.5 \%$ or even lower [17-22]. The authors' results using mid-gestation bone marrow were similar, with various measures of cell and progenitor recovery using DMSO concentrations of $5-7.5 \%$ as good as those obtained with $10 \%$ DMSO. The effect of DMSO concentration on the recovery of cryopreserved HSCs was evaluated using a xenogeneic transplant model. HSCs were defined by their ability to engraft NSG mice for a minimum of 12 weeks, with evidence of multi-lineage engraftment measured by the presence of myeloid, B-lymphoid and erythroid cells. Detection of CD34 $4^{+/}$ ${ }^{++}$progenitors was a fourth engraftment criterion to further demonstrate active hematopoiesis. No significant differences in the frequencies of HSCs, as measured by ELDA [28], were apparent among the DMSO concentrations tested. Indeed, although not significant, the estimated frequencies of HSCs were up to 2.4-fold higher using 5-7.5\% DMSO compared with $10 \%$ DMSO. The levels of human engraftment also tended to be higher in mice receiving grafts cryopreserved with $5 \%$ or $7.5 \%$
DMSO, further indicating that cryopreservation can be effectively performed using these lower DMSO concentrations without loss of HSCs.

The criteria used to assess human HSC engraftment in immunodeficient mice are not standardized, vary by laboratory and have evolved with the development of immunodeficient mouse strains. Some past studies have simply evaluated overall human engraftment $\left(\mathrm{CD} 45^{+}\right)$or myeloid $\left(\mathrm{CD}_{3} 3^{+}\right)$and lymphoid $\left(\mathrm{CD}_{1} 9^{+}, \mathrm{CD}^{+}\right)$engraftment combined $[35,36]$, whereas others have analyzed a wider spectrum of blood cells $[37,38]$. The authors have previously observed that some engrafted mice may harbor only a single lineage of lymphocytes or monocytic cells; thus, longevity of these cells makes their detection alone insufficient evidence for HSC engraftment [34]. Although erythrocytes have a long life span, their survival in the circulation of NSG mice is short $[33,39]$. Thus, the authors' observation of fewer of these cells in the spleen than the bone marrow was not surprising. Nonetheless, the detection of erythropoiesis in the bone marrow, especially when combined with the observation of 
A

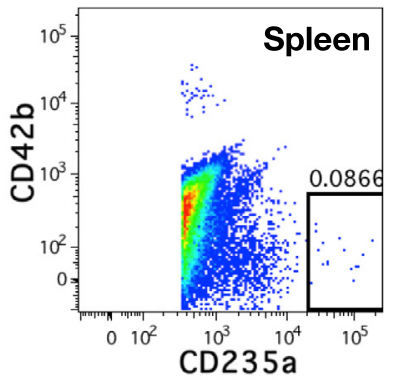

B

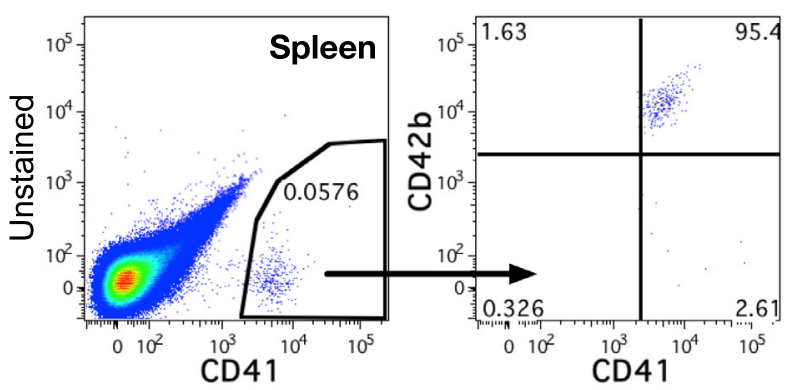

C

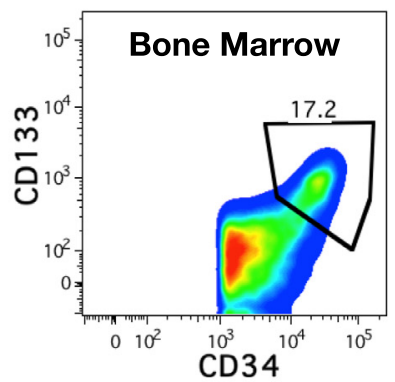

D

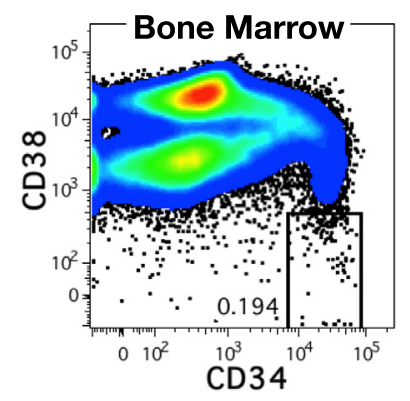

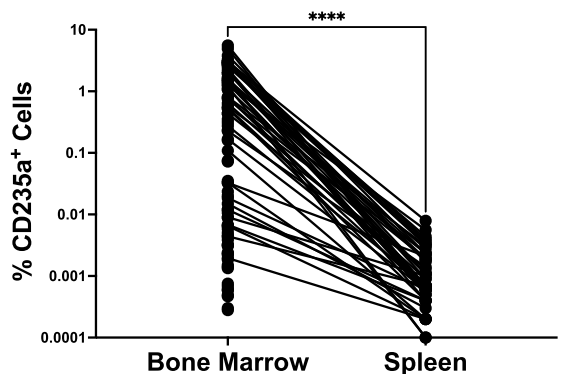
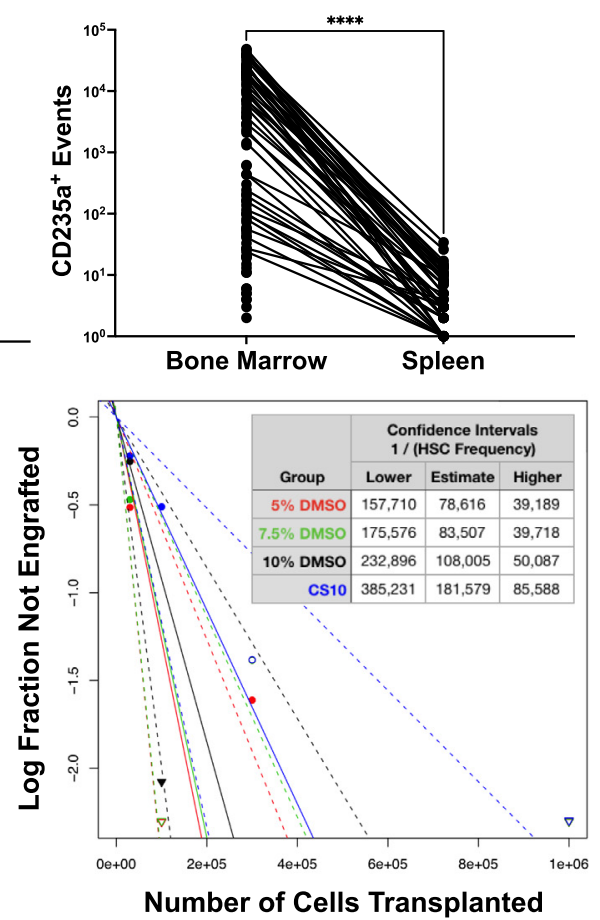

Number of Cells Transplanted
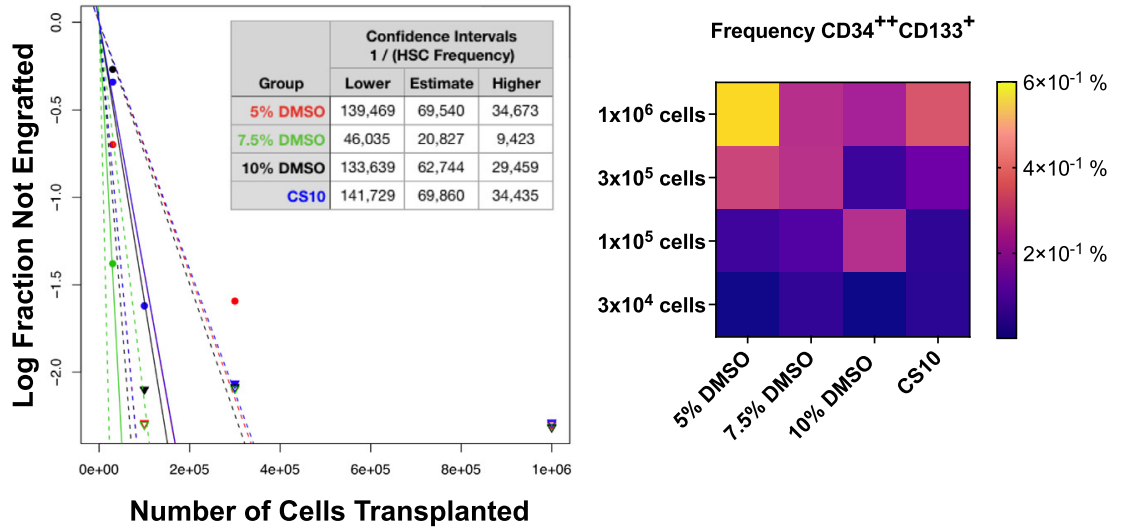
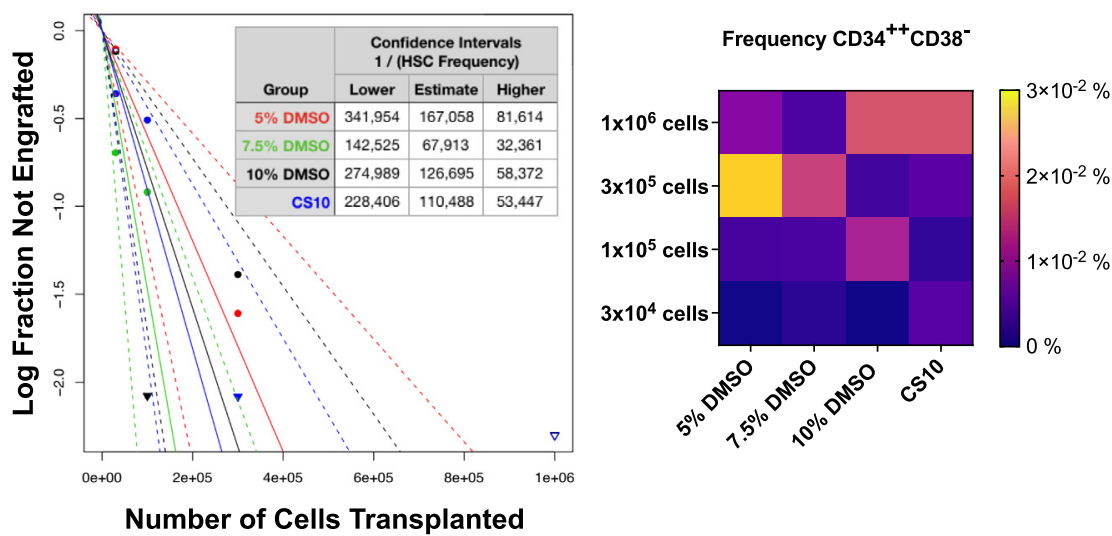

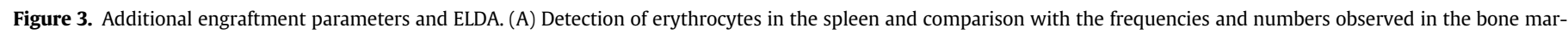

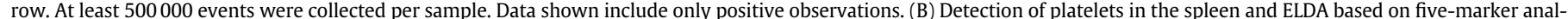

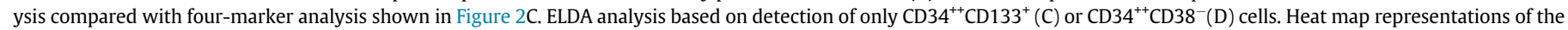
mean frequencies of $\mathrm{CD} 34^{++} \mathrm{CD} 133^{+}$and $\mathrm{CD} 34^{++} \mathrm{CD} 38^{-}$cells in the bone marrow are shown for each of the transplant groups. ${ }^{* * * *} P<0.0001$. CS10, CryoStor CS10.

$\mathrm{CD}^{+} 4^{+}$cells, is a reliable indicator of ongoing hematopoiesis and HSC engraftment.

The authors tested other criteria for determining HSC engraftment. Expanding the criteria to include platelets reduced the frequency estimates of HSCs but did not change the overall findings that showed reduced DMSO percentages to be as effective as $10 \%$ DMSO in cryopreservation. Using the observed presence of primitive progenitor compartments $\left(\mathrm{CD} 34^{++} \mathrm{CD} 133^{+}\right.$and $\mathrm{CD} 34^{++} \mathrm{CD} 38^{-}$cells) 
rather than multi-lineage analysis as evidence of HSC engraftment also did not challenge the conclusions of this study, with the $7.5 \%$ DMSO group showing the highest recovery of HSCs. However, the $5 \%$ DMSO group still contained numbers of HSCs that were similar to those observed in the two groups with 10\% DMSO.

\section{Conclusions}

This study provides quantitative evidence that human HSCs are effectively cryopreserved using DMSO concentrations as low as 5\%. There are ongoing efforts to further reduce DMSO toxicity by reducing concentrations through the addition of other cryoprotective agents or by washing the thawed cells $[5,10]$. The design of new cryopreservation agents or methods of freezing may eventually lead to DMSO-free cryopreservation of HSCs [10,40,41]. Until such time, current clinical practice can benefit from reductions in the concentration of DMSO used for HSC cryopreservation.

\section{Funding}

This work was supported in part by Vitalant Inc. KMA received support from a Bridges to Stem Cell Research and Therapy award (EDUC208400) from the California Institute for Regenerative Medicine. The content is solely the responsibility of the authors and does not necessarily represent the official views of the California Institute for Regenerative Medicine or any other agency of the State of California.

\section{Declaration of Competing Interest}

The authors have no commercial, proprietary or financial interest in the products or companies described in this article.

\section{Author Contributions}

Conception and design of the study: RG, MOM and PJN. Acquisition of data: RG, KMA, AH and MOM. Analysis and interpretation of data: RG, KMA, AH, MOM and PJN. Drafting or revising the manuscript: RG, KMA, $\mathrm{AH}, \mathrm{PJN}$ and MOM. All authors have approved the final article.

\section{Acknowledgments}

The authors thank the staff and faculty at San Francisco General Hospital Women's Options Center for their assistance in the collection of human bone marrow.

\section{Supplementary materials}

Supplementary material associated with this article can be found in the online version at doi:10.1016/j.jcyt.2021.07.007.

\section{References}

[1] Copelan EA. Hematopoietic stem-cell transplantation. $N$ Engl J Med 2006;354:1813-26.

[2] Pegg DE. Principles of cryopreservation. Methods Mol Biol 2015;1257:3-19.

[3] McDonald GR, Hudson AL, Dunn SM, You H, Baker GB, Whittal RM, et al. Bioactive contaminants leach from disposable laboratory plasticware. Science 2008:322:917.

[4] Verheijen M, Lienhard M, Schrooders Y, Clayton O, Nudischer R, Boerno S, et al. DMSO induces drastic changes in human cellular processes and epigenetic landscape in vitro. Sci Rep 2019;9:4641.

[5] Awan M, Buriak I, Fleck R, Fuller B, Goltsev A, Kerby J, et al. Dimethyl sulfoxide: a central player since the dawn of cryobiology, is efficacy balanced by toxicity. Regen Med 2020;15:1463-91.

[6] Sauer-Heilborn A, Kadidlo D, McCullough J. Patient care during infusion of hematopoietic progenitor cells. Transfusion 2004;44:907-16.
[7] Shu Z, Heimfeld S, Gao D. Hematopoietic SCT with cryopreserved grafts: adverse reactions after transplantation and cryoprotectant removal before infusion. Bone Marrow Transplant 2014:49:469-76.

[8] Morris C, de Wreede L, Scholten M, Brand R, van Biezen A, Sureda A, et al. Should the standard dimethyl sulfoxide concentration be reduced? Results of a European Group for Blood and Marrow Transplantation prospective noninterventional study on usage and side effects of dimethyl sulfoxide. Transfusion 2014;54:2514-22.

[9] Kollerup Madsen B, Hilscher M, Zetner D, Rosenberg J. Adverse reactions of dimethyl sulfoxide in humans: a systematic review. F1000Res. 2018;7:1746.

[10] Hornberger K, Yu G, McKenna D, Hubel A. Cryopreservation of Hematopoietic Stem Cells: Emerging Assays, Cryoprotectant Agents, and Technology to Improve Outcomes. Transfus Med Hemother 2019;46:188-96.

[11] Cavins JA, Kasakura S, Thomas ED, Ferrebee JW. Recovery of lethally irradiated dogs following infusion of autologous marrow stored at low temperature in dimethyl sulphoxide. Blood 1962;20:730-4.

[12] MJ Ashwood-Smith. The preservation of bone marrow. Cryobiology 1964;13:61-3.

[13] Davis JM, Rowley SD, Braine HG, Piantadosi S, Santos GW. Clinical toxicity of cryopreserved bone marrow graft infusion. Blood 1990;75:781-6.

[14] Branch DR, Calderwood S, Cecutti MA, Herst R, Solh H. Hematopoietic progenitor cells are resistant to dimethyl sulfoxide toxicity. Transfusion 1994:34:887-90.

[15] Valeri CR, Pivacek LE. Effects of the temperature, the duration of frozen storage and the freezing container on in vitro measurements in human peripheral blood mononuclear cells. Transfusion 1996;36:303-8.

[16] Cilloni D, Garau D, Regazzi E, Sammarelli G, Savoldo B, Caramatti C, et al. Primitive hematopoietic progenitors within mobilized blood are spared by uncontrolled rate freezing. Bone Marrow Transplant 1999;23:497-503.

[17] Zeisberger SM, Schulz JC, Mairhofer M, Ponsaerts P, Wouters G, Doerr D, et al. Biological and physicochemical characterization of a serum- and xeno-free chemically defined cryopreservation procedure for adult human progenitor cells. Cell Transplant 2011;20:1241-57.

[18] Galmés A, Besalduch J, Bargay J, Matamoros N, Durán MA, Morey M, et al. Cryopreservation of hematopoietic progenitor cells with 5-percent dimethyl sulfoxide at -80 degrees $C$ without rate-controlled freezing. Transfusion 1996:36:794-7.

[19] Katayama Y, Yano T, Bessho A, Deguchi S, Sunami K, Mahmut N, et al. The effects of a simplified method for cryopreservation and thawing procedures on peripheral blood stem cells. Bone Marrow Transplant 1997;19:283-7.

[20] Halle P, Tournilhac O, Knopinska-Posluszny W, Kanold J, Gembara P, Boiret N, et al. Uncontrolled-rate freezing and storage at -80 degrees C, with only 3.5-percent DMSO in cryoprotective solution for 109 autologous peripheral blood progenitor cell transplantations. Transfusion 2001;41:667-73.

[21] Smagur A, Mitrus I, Giebel S, Sadus-Wojciechowska M, Najda J, Kruzel T, et al. Impact of different dimethyl sulphoxide concentrations on cell recovery, viability and clonogenic potential of cryopreserved peripheral blood hematopoietic stem and progenitor cells. Vox Sang 2013;104:240-7.

[22] Abrahamsen JF, Bakken AM, Bruserud Ø. Cryopreserving human peripheral blood progenitor cells with 5-percent rather than 10-percent DMSO results in less apoptosis and necrosis in CD34+ cells. Transfusion 2002;42:1573-80.

[23] Galmés A, Gutiérrez A, Sampol A, Canaro M, Morey M, Iglesias J, et al. Long-term hematological reconstitution and clinical evaluation of autologous peripheral blood stem cell transplantation after cryopreservation of cells with $5 \%$ and $10 \%$ dimethylsulfoxide at -80 degrees $\mathrm{C}$ in a mechanical freezer. Haematologica 2007;92:986-9.

[24] Akkök CA, Liseth K, Nesthus I, Løkeland T, Tefre K, Bruserud O, et al. Autologous peripheral blood progenitor cells cryopreserved with 5 and 10 percent dimethyl sulfoxide alone give comparable hematopoietic reconstitution after transplantation. Transfusion 2008;48:877-83.

[25] Mitrus I, Smagur A, Fidyk W, Czech M, Prokop M, Chwieduk A, et al. Reduction of DMSO concentration in cryopreservation mixture from $10 \%$ to $7.5 \%$ and $5 \%$ has no impact on engraftment after autologous peripheral blood stem cell transplantation: results of a prospective, randomized study. Bone Marrow Transplant 2018:53:274-80.

[26] Windrum P, Morris TC, Drake MB, Niederwieser D, Ruutu T, CLWPCS EBMT. Variation in dimethyl sulfoxide use in stem cell transplantation: a survey of EBMT centres. Bone Marrow Transplant 2005;36:601-3.

[27] Beksac M, Preffer F. Is it time to revisit our current hematopoietic progenitor cell quantification methods in the clinic. Bone Marrow Transplant 2012;47:1391-6.

[28] Hu Y, Smyth GK. ELDA: extreme limiting dilution analysis for comparing depleted and enriched populations in stem cell and other assays. J Immunol Methods 2009;347:70-8.

[29] Golfier F, Bárcena A, Harrison MR, Muench MO. Fetal bone marrow as a source of stem cells for in utero or postnatal transplantation. Br J Haematol 2000;109:173-81.

[30] Varga NL, Bárcena A, Fomin ME, Muench MO. Detection of human hematopoietic stem cell engraftment in the livers of adult immunodeficient mice by an optimized flow cytometric method. Stem Cell Stud 2010;1:e5.

[31] Golfier F, Bárcena A, Cruz J, Harrison M, Muench M. Mid-trimester fetal livers are a rich source of CD34+/++ cells for transplantation. Bone Marrow Transplant 1999;24:451-61.

[32] Muench MO, Roncarolo MG, Menon S, Xu Y, Kastelein R, Zurawski S, et al. FLK-2/ FLT-3 ligand regulates the growth of early myeloid progenitors isolated from human fetal liver. Blood 1995;85:963-72.

[33] Blessinger SA, Tran JQ Jackman RP, Gilfanova R, Rittenhouse J, Gutierrez AG, et al. Immunodeficient mice are better for modeling the transfusion of human blood components than wild-type mice. PLoS One 2020;15:e0237106. 
[34] Muench MO, Kapidzic M, Gormley M, Gutierrez AG, Ponder KL, Fomin ME, et al. The human chorion contains definitive hematopoietic stem cells from the fifteenth week of gestation. Development 2017;144:1399-411.

[35] Kimura T, Matsuoka Y, Murakami M, Kimura T, Takahashi M, Nakamoto T, et al. In vivo dynamics of human cord blood-derived CD34(-) SCID-repopulating cells using intra-bone marrow injection. Leukemia 2010;24:162-8.

[36] Qiu J, Gjini J, Arif T, Moore K, Lin M, Ghaffari S. Using mitochondrial activity to select for potent human hematopoietic stem cells. Blood Adv 2021;5:1605-16.

[37] Takahashi M, Matsuoka Y, Sumide K, Nakatsuka R, Fujioka T, Kohno H, et al. CD133 is a positive marker for a distinct class of primitive human cord blood-derived CD34-negative hematopoietic stem cells. Leukemia 2014;28:1308-15.
[38] Ivanovs A, Rybtsov S, Anderson RA, Medvinsky A. Vast Self-Renewal Potential of Human AGM Region HSCs Dramatically Declines in the Umbilical Cord Blood. Stem Cell Reports 2020;15:811-6.

[39] Hu Z, Van Rooijen N, Yang Y-G. Macrophages prevent human red blood cell reconstitution in immunodeficient mice. Blood 2011;118:5938-46.

[40] Murray KA, Gibson MI. Post-Thaw Culture and Measurement of Total Cell Recovery Is Crucial in the Evaluation of New Macromolecular Cryoprotectants. Biomacromolecules 2020;21:2864-73.

[41] Gilfanova R, Callegari A, Childs A, Yang G, Luarca M, Gutierrez AG, et al. A bioinspired and chemically defined alternative to dimethyl sulfoxide for the cryopreservation of human hematopoietic stem cells [published online ahead of print June 21, 2021]. Bone Marrow Transplant 2021 